\title{
Effect of Oral Intake of A Mixture Containing Natural Citrus Peel Extract, Vitamin C, and L-Cystine on Skin Brightness in Healthy Women
}

\author{
Jeong Kee Kim', Nok Hyun Park ${ }^{1}$, Jae Sung Hwang ${ }^{1}$, Ji Hoon Baek ${ }^{2}$, Hyun Woo Jeong ${ }^{3, *}$ \\ ${ }^{1}$ Department of Genetic Engineering \& Graduate School of Biotechnology, College of Life Sciences, \\ Kyung Hee University, Yongin, Korea \\ ${ }^{2}$ Dermapro Skin Research Center, Dermapro Ltd., Seoul, Korea \\ ${ }^{3}$ Vitalbeautie Research Institute, Amorepacific Corporation R\&D center, Yongin, Korea \\ *Corresponding author: misterjay@amorepacific.com
}

Received October 03, 2018; Revised November 06, 2018; Accepted November 15, 2018

\begin{abstract}
Citrus peel extract (CPE) has several bioactivities that encompass anti-oxidation, anti-inflammation and anti-melanogenic effect. However, its usage in functional food has been difficult due to uncommon evidence in human trial. The reason of this study is to evaluate the safety and skin brightening effects of natural CPE in human subjects. To enhance its effectiveness in clinical trial, we also used both vitamin C for anti-oxidation and L-cystine for decreasing melanin biosynthesis. All subjects administered 1 test capsule (AP-BF02 including 100mg of CPE, $125 \mathrm{mg}$ of vitamin C, $60 \mathrm{mg}$ of L-cystine) or placebo for two months. We objectively measured changes in melanin index (MI), skin lightness $\left(\mathrm{L}^{*}\right)$, and skin color $\left(\mathrm{ITA}^{\mathrm{O}}\right)$. The two investigators also used subjective ratings to analyze skin pigmentation. The MI values were significantly lower in test group, compared with that in placebo group from 4 weeks after. In addition, AP-BF02-intake group had significant improvement in lightness and color at the end of examine period. Consequently, oral supplementation with AP-BF02 can brighten human skin in healthy women without adverse effect.
\end{abstract}

Keywords: melanin, skin brightening, AP-BF02, citrus peel extract, human, natural skin food

Cite This Article: Jeong Kee Kim, Nok Hyun Park, Jae Sung Hwang, Ji Hoon Baek, and Hyun Woo Jeong, "Effect of Oral Intake of A Mixture Containing Natural Citrus Peel Extract, Vitamin C, and L-Cystine on Skin Brightness in Healthy Women.” Journal of Food and Nutrition Research, vol. 6, no. 10 (2018): 655-659. doi: 10.12691/jfnr-6-10-6.

\section{Introduction}

Reactive oxygen species (ROS) which are produced excessively in the cells are involved in the process of ultraviolet (UV) exposure-related skin aging. Especially, UVB-induced production of $\mathrm{H}_{2} \mathrm{O}_{2}$ in keratinocytes causes melanocyte degeneration in the skin of patients with vitiligo [1,2]. Therefore, melanogenesis associated with ROS could be suppressed by antioxidant treatment because tyrosinase, the key enzyme of melanogenesis, prefers superoxide radical $\left(\mathrm{O}_{2}^{-}\right)$over oxygen $\left(\mathrm{O}_{2}\right)$ for its activity [3]. Redox agents could also influence skin pigmentation by interacting copper at the active site of tyrosinase or with o-quinones to impede the oxidative polymerization of melanin intermediates. Antioxidant could also reduce the direct photooxidation of pre-existing melanin. For these reason, common antioxidants are used in skin-brightening formulations such as vitamin $\mathrm{E}$, vitamin $\mathrm{C}$ and vitamin $\mathrm{B}$ $[4,5]$.

Citrus fruits are representative dietary sources of antioxidants and have been used for traditional medicines in Eastern Asian countries including Japan, China, and Korea. Especially, citrus peels have been identified and reported to possess diverse biological activities [6,7]. According to recent study, the various components of citrus peel extract (CPE) are suggested to exert inhibitory effects in melanogenesis through diverse mechanisms including reduction of melanin content, suppression of melanosome transport, and elimination of intracellular ROS [7]. Therefore, as a mixture of functional ingredients, CPE is expected to possess a strong ability to brighten skin in living body [8].

Another pathway for skin brightening is related to the pheomelanin pathway, a branch pathway from the eumelanin pathway at the L-dopaquinone step with the presence of cysteine. L-cystine, a dimer of cysteine, could regulate melanogenesis pathway because cysteine reacts with L-dopaquinone to form cysteinyl-dopa which is converted and polymerized to pheomelanin and finally decreases melanin level [9].

Oral supplementation for the protection against skin damage has attracted attention to food for skin benefit. For systemic photo-protection, several compounds have been assessed for their ability to provide photo-protective 
activity after oral administration to develop new functiona foods for skin [10]. The purpose of current research was to investigate the beneficial effect of a novel, natural mixture supplement (AP-BF02) consisting of CPE, vitamin C, and L-cystine on skin brightening in clinical trial.

\section{Materials and Methods}

\subsection{Study Design with Human Subjects}

The study was approved by the local ethics committee (Dermapro Ltd. Institutional Review Board, DEFFFHSLIT030(1)-10054), and conducted in accordance with good clinical practice guidelines. We screened 80 healthy female candidates and selected 65 subjects who met the criterion of melanin index values of 100 to 300. The study's exclusion criteria were as follows: pregnancy of nursing a child; medication or a medical history that may affect the skin's response; any active skin disease that may interfere with the study's aim; the use of immunosuppressive therapies within 3 months of the start of the study; the use of anti-inflammatory, corticoid, retinoid, or laser therapies within 1 month of the start of the study; participation in a previous study without an appropriate intervening period between the studies; the presence of a chronic disease, including diabetes, asthma, and high blood pressure; the presence of serious renal disorders of hepatic dysfunction; the presence of damaged skin in or around the measuring site, which included sunburn, uneven skin tones, tatis, scars, of other forms of disfiguration; or excessive exposure to sunlight of UV radiation.

\subsection{Test Samples}

Both the test capsules and the control capsules were provided by Suheung Capsule Co. Ltd. (Osong, Korea). The test capsule was composed of $14.28 \%$ (w/w \%) CPE ( $>20 \%$ of hesperidin, Bioland Co. Ltd., Cheonan, Korea), 17.85\% vitamin C (DSM Nutri. Prod., Derbyshire, UK) and $8.57 \%$ L-cystine (Daebong LS Co. Ltd., Incheon, Korea) together with other ingredients, including soy bean oil, bees wax, soy lecithin and cacao color (Table 1). The control capsule did not contain those three active ingredients above. Each subject of test group administered daily $100 \mathrm{mg}$ of standardized CPE $125 \mathrm{mg}$ of vitamin C, and $60 \mathrm{mg}$ of L-cystine as active compounds.

\subsection{Objective Evaluations with Instruments}

The subjects have been advised to rest inside the testing room for about 20 minutes for acclimation before the instrumental measurements. Skin-brightening efficacy was examined by the melanin index (MI) using a Mexameter MX18 (Courage + Khazaka Electronic GmbH, Cologne, Germany). Brightening efficacy became examined in the cheekbone area. The MI recorded was the average of three individual data and $\Delta \mathrm{MI}$ values (MI value on the week of observation - MI value before intake) were calculated for statistical analysis. The skin color of each subject became analyzed using a Spectrophotometer CM-2500d (Konica Minolta INC., Osaka, Japan). The effects have been expressed using the value of lightness $\left(\mathrm{L}^{*}\right)$ and the individual typology angles (ITA ${ }^{\mathrm{O}}$ ) calculated using $\mathrm{a}^{*}$ (green or red) and $\mathrm{b}^{*}$ (blue or yellow). Measurements were performed at baseline before administration, on weeks 4 and on week 8. For the analysis, each measurement was performed three times and the average values of every measurement were used. The ITA ${ }^{\mathrm{O}}$ were calculated using the following equation: ITA ${ }^{\mathrm{O}}=$ [Arc-tangent $\left.\left\{\left(\mathrm{L}^{*}-50\right) / \mathrm{b}^{*}\right\}\right]$ $\times 180 \div 3.14159$. The $\Delta \mathrm{L}^{*}$ values $\left(\mathrm{L}^{*}\right.$ value on the week of observation $-\mathrm{L}^{*}$ value before intake) and $\Delta \mathrm{ITA}^{\mathrm{O}}$ values $\left(\right.$ ITA $^{\mathrm{O}}$ value on the week of observation - ITA $^{\mathrm{O}}$ value before intake) were also calculated.

\subsection{Subjective Evaluations}

Skin brightening and improvement in cheekbone's color were evaluated subjectively by the two investigators in accordance with the following scoring pattern, continuous 9-point scale. (9: black and dark; 5: medium darkness; 1: bright and light). The $\Delta$ Pigmentation scores (Pigmentation score on the week of observation - Pigmentation score before intake) were also calculated.

\subsection{Statistical Analysis}

All data based on the measurement and assessment are expressed as mean $\pm \mathrm{SD}$, but data about delta-value are expressed as mean \pm SE. Statistical analyses were performed using the SPSS program (SPSS 18.0) with original \& delta value of each index. One-way ANOVA and paired t-tests were used to compare difference of skin parameters within and between groups. $\mathrm{P}$ values $<0.05$ were considered to be statistically significant.

\section{Results and Discussion}

\subsection{Characteristics of Study Subjects}

All subjects recruited were randomly assigned to one of the two groups for 2 months: (1) daily oral supplementation with a placebo capsule (CON) or (2) daily oral supplementation with one 700mg capsule of mixed ingredients (AP-BF02) (Table 1). All subjects completed the study and were monitored by the investigator during the study for the development of adverse effect (Figure 1). No adverse reactions related to AP-BF02 were reported during the study period. The baseline characteristics of the 65 female subjects are shown in Table 2. Mean age was $41.37 \pm 3.19$ years and skin types among all subjects are mainly "fairy dry skin” and "normal skin”.

Table 1. Formula of the test sample. All subjects were administered one capsule once per day

\begin{tabular}{|l|c|c|}
\hline \multirow{2}{*}{ Ingredients (700mg/capsule) } & \multicolumn{2}{|c|}{ Contents (w/w \%) } \\
\cline { 2 - 3 } & Placebo (CON) & AP-BF02 \\
\hline Soy bean oil & 52.68 & 52.68 \\
\hline Bees wax & 4 & 4 \\
\hline Soy lecithin & 1.9 & 1.9 \\
\hline Citrus peel extract & - & 14.28 \\
\hline Vitamin C & - & 17.85 \\
\hline L-cystine & - & 8.57 \\
\hline Cacao color & 9.3 & 0.72 \\
\hline Gardenia yellow color & 32.12 & - \\
\hline Total & 100 & 100 \\
\hline
\end{tabular}




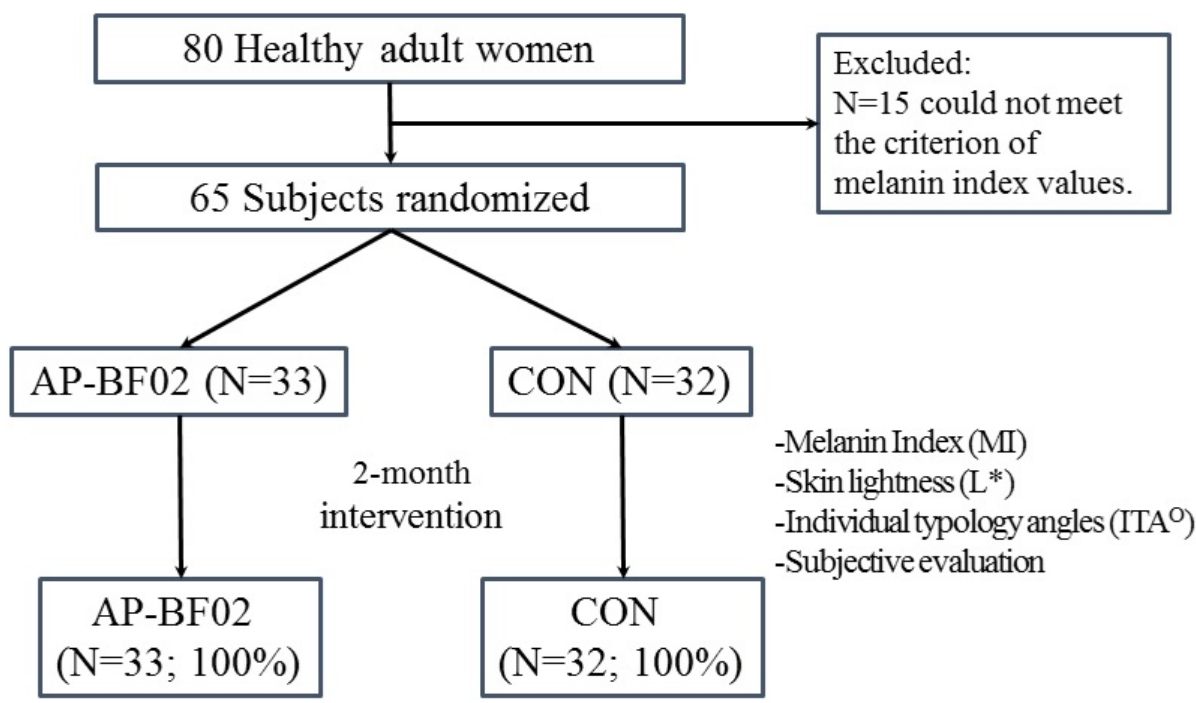

Figure 1. Study flow chart. 65 healthy women were recruited and randomly assigned to either CPE mixture (AP-BF02) or placebo (CON). All subjects finished the 2-month trial without dropout

Table 2. Baseline characteristics of the 65 female subjects

\begin{tabular}{|l|c|}
\hline Age (years), mean \pm SD & $41.37 \pm 3.19$ \\
\hline Age, n (\%) & \\
Twenties (20’s) & $1(1.5)$ \\
Thirties (30’s) & $14(21.5)$ \\
Forties (40’s) & $50(76.9)$ \\
\hline Type of face skin, n (\%) & \\
Fairly dry & $29(44.6)$ \\
Normal & $25(38.5)$ \\
Fairly oily & $2(3.1)$ \\
Slight oily & $9(13.9)$ \\
Sensitive skin & 0 \\
\hline
\end{tabular}

\subsection{Objective Efficacy}

Table 3 shows the results based on the Mexameter measurements. The $\Delta \mathrm{MI}$ values of the placebo control decreased little after 8 weeks' intake (Week 4: $-1.1706 \pm$ 0.58348; Week 8: $-0.7973 \pm 0.78342$ ). In contrast, subjects that administered AP-BF02 showed a clear decrease in the $\triangle \mathrm{MI}$ values, starting after 4 weeks of the study period (Week 4: -2.8328 \pm 0.59253; Week 8: -4.8641 \pm 0.79556 ). After 8 weeks, the $\Delta \mathrm{MI}$ values of the subjects that supplemented AP-BF02 were significantly lower than those of subjects received placebo control $(p<0.01)$.

Table 3. Changes in melanin index (MI) values with AP-BF02 supplement

\begin{tabular}{|l|c|c|}
\hline Group & MI & $\Delta$ MI \\
\hline Placebo control & & - \\
Week 0 & $201.83 \pm 37.68$ & $-1.1706 \pm 0.58348$ \\
Week 4 & $200.66 \pm 36.49$ & $-0.7973 \pm 0.78342$ \\
Week 8 & $201.03 \pm 35.53$ & - \\
\hline AP-BF02 & $200.04 \pm 25.97$ & $-2.8328 \pm 0.59253^{\text {a,b }}$ \\
Week 0 & $197.21 \pm 25.16^{\text {a }}$ & $-4.8641 \pm 0.79556^{\text {a,c }}$ \\
Week 4 & $195.18 \pm 24.54^{\text {a }}$ & \\
Week 8 &
\end{tabular}

a Significantly different at $\mathrm{p}<0.05$ (versus week 0 )

${ }^{\mathrm{b}}$ Significantly different at $\mathrm{p}<0.05$ (versus control group at week 4)

c Significantly different at $\mathrm{p}<0.01$ (versus control group at week 8).

An improvement of brightness was observed inside the cheekbone area of the subjects of test group compared with that of placebo controlled group. The results based on the Spectrophotometer CM2500d measurement are shown in Table 4. Although the difference of $\mathrm{L}^{*}$ is not big, the $\Delta \mathrm{L}^{*}$ value of the AP-BF02 group was significantly higher than that of the placebo group after Week 8 ( $p<0.05)$.

Table 4. Changes in lightness values $\left(L^{*}\right)$ and $\Delta L^{*}$ with AP-BF02 supplement

\begin{tabular}{|l|c|c|}
\hline Group & $\mathrm{L}^{*}$ & $\Delta \mathrm{L}^{*}$ \\
\hline Placebo control & & - \\
Week 0 & $59.81 \pm 2.25$ & $0.103939 \pm 0.08411$ \\
Week 4 & $59.92 \pm 2.29$ & $0.128788 \pm 0.10641$ \\
Week 8 & $59.94 \pm 2.32$ & - \\
\hline AP-BF02 & & \\
Week 0 & $60.22 \pm 2.04$ & $0.265937 \pm 0.08541^{\mathrm{a}}$ \\
Week 4 & $60.49 \pm 1.95^{\mathrm{a}}$ & $0.430625 \pm 0.10623^{\mathrm{a}, \mathrm{b}}$ \\
Week 8 & $60.65 \pm 2.04^{\mathrm{a}}$ & \\
\hline
\end{tabular}

a Significantly different at $\mathrm{p}<0.05$ (versus week 0 )

${ }^{\mathrm{b}}$ Significantly different at $\mathrm{p}<0.05$ (versus control group at week 8).

Using spectrophotometer, the skin color parameters were measured at each time, and the ITA ${ }^{\mathrm{O}}$ were calculated. Table 5 shows that the ITA $^{\mathrm{O}}$ of test group on week 4 and week 8 significantly higher than the ITA $^{\mathrm{O}}$ measured before intake. In addition, the $\Delta \mathrm{ITA}^{\mathrm{O}}$ in the test group were significantly greater than those of the control group on weeks 4 and $8(\mathrm{p}<0.05)$. Figure 2 also shows the $\Delta \mathrm{L}^{*}$ and $\Delta$ ITA $^{\mathrm{O}}$ plotted against time. Therefore, consumption of AP-BF02 is considered to have a useful effect of skin depigmenting in human.

Table 5. Changes in $\operatorname{ITA}^{\circ}$ and $\triangle \mathrm{ITA}^{\circ}$ with AP-BF02 supplement

\begin{tabular}{|l|c|c|}
\hline Group & ITA $^{\mathrm{O}}$ & $\Delta \mathrm{ITA}^{\mathrm{O}}$ \\
\hline Placebo control & & - \\
Week 0 & $25.53 \pm 5.61$ & $0.120468 \pm 0.2082$ \\
Week 4 & $25.65 \pm 5.57$ & $0.00066 \pm 0.29148$ \\
Week 8 & $25.53 \pm 5.36$ & - \\
\hline AP-BF02 & $26.02 \pm 5.17$ & \\
Week 0 & $26.82 \pm 5.31^{\mathrm{a}}$ & $0.800915 \pm 0.21142^{\mathrm{a}, \mathrm{b}}$ \\
Week 4 & $26.91 \pm 5.29^{\mathrm{a}}$ & $0.89213 \pm 0.296^{\mathrm{a}, \mathrm{b}}$ \\
\hline
\end{tabular}

${ }^{\text {a }}$ Significantly different at $\mathrm{p}<0.05$ (versus week 0 )

${ }^{\mathrm{b}}$ Significantly different at $\mathrm{p}<0.05$ (versus control group at each week). 
(a)

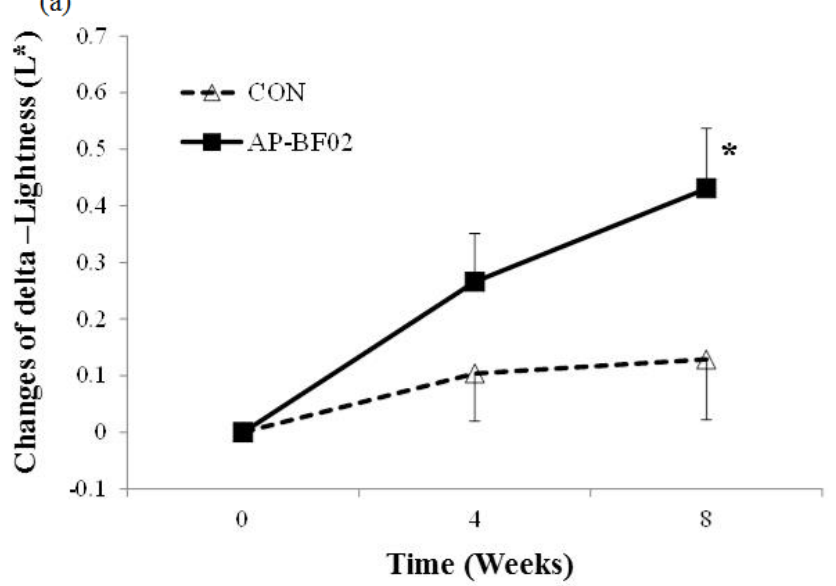

(b) 1.5

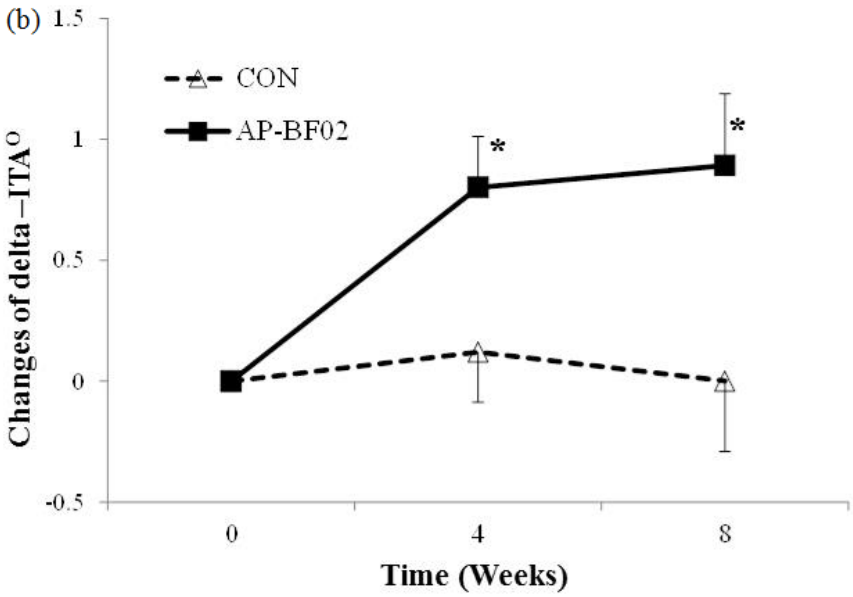

Figure 2. Changes in the lightness $\left(\mathrm{L}^{*}\right)$ and the Individual typology angles $\left(\mathrm{ITA}^{\mathrm{O}}\right)$ values after intake of the control and the test products. Trend of mean values of $\Delta \mathrm{L}^{*}$ and $\Delta \mathrm{ITA} \mathrm{A}^{\mathrm{O}}$ versus time was represented in (a) and (b). Data are presented as the means \pm standard errors of the mean. ${ }^{*} \mathrm{p}<0.05$ versus the control group at each time point

\subsection{Subjective Efficacy}

The investigators subjectively evaluated the skin benefits of the AP-BF02 and placebo supplement in accordance with a scoring scale (see "Materials and Methods" section). Scores of 2 or 1 were not recorded by any of the investigators. In the investigator's assessment of skin, pigmentation scores decreased slightly after 8 weeks' supplementation of the placebo control (Week 0: $4.64 \pm$ 0.87; Week 8: 4.56 \pm 0.94 ) (Table 6). In contrast, subjects that administered AP-BF02 showed a significant decrease in pigmentation scores after 8 weeks of the study period (Week 0: $4.59 \pm$ 0.80; Week 8: $4.36 \pm 0.72$ ). Table 6 also shows that $\Delta$ Pigmentation scores of test group significantly decreased at Week 8 versus control group (CON: -0.07576 \pm 0.03815; AP-BF02: $-0.23438 \pm 0.06513$; $\mathrm{p}<0.05$ ).

This analysis indicates that one in four investigators can reduce one grade when evaluating the same subject supplemented AP-BF02. Recently, Jo et al. suggested that the limit of perception for the pigmentation degree was 0.5 , which was related to the MI of $8.03, L^{*}$ value of 0.64 [11].

Table 6. Depigmenting effects of AP-BF02 intake on skin as scored by investigators

\begin{tabular}{|c|c|c|}
\hline Group & Pigmentation score & $\Delta$ Pigmentation score \\
\hline Placebo control & & - \\
Week 0 & $4.64 \pm 0.87$ & - \\
Week 4 & $4.58 \pm 0.89$ & $-0.06061 \pm 0.03756$ \\
Week 8 & $4.56 \pm 0.94$ & $-0.07576 \pm 0.03815$ \\
\hline AP-BF02 & & - \\
Week 0 & $4.59 \pm 0.80$ & - \\
Week 4 & $4.52 \pm 0.76$ & $-0.07813 \pm 0.03815$ \\
Week 8 & $4.36 \pm 0.72^{\mathrm{a}}$ & $-0.23438 \pm 0.06513^{\mathrm{a}, \mathrm{b}}$ \\
\hline
\end{tabular}

a Significantly different at $\mathrm{p}<0.05$ (versus week 0 )

${ }^{\mathrm{b}}$ Significantly different at $\mathrm{p}<0.05$ (versus control group at week 8).

In our results, the difference of pigmentation score, MI and $L^{*}$ was $-0.23,-4.9$, and 0.43 , and these corresponds to about $50 \%$ of perception limit suggested above. Because these are lower than expected, we conducted a subgroup analysis for subjects having the pigmentation scores from 5 to 9 (CON: $n=13$; AP-BF02: $n=13)$. In this subgroup analysis at Week $8, \Delta$ Pigmentation scores of test group is smaller than those obtained by previous analysis (CON: $-0.000 \pm 0.13277$; AP-BF02: $-0.5000 \pm 0.13277$; $\mathrm{p}<0.01$ ). This means that one of two investigators can reduce one point for the same person who has darker skin and intakes AP-BF02 continuously during 8 weeks. This implies that the chances of noticing the improvement of skin pigmentation would be doubled in the participants with darker skin than the ordinary skin.

We evaluated the effects of the oral intake of a mixture formula containing CPE, vitamin $\mathrm{C}$ and L-cystine on the skin color for 8 weeks. We calculated the MI value, $\mathrm{L}^{*}$, and ITA $^{\mathrm{O}}$ as an objective indicator, and added the subjective assessments (pigmentation score) by the investigators. These evaluations proved the depigmenting effect of AP-BF02, and we suggest that the intake of AP-BF02 should brighten skin effectively.

Melanin in human skin is a polymer of various indole compounds synthesized from L-tyrosine. Two different types of melanin - eumelanin, which is black or brown, and pheomelanin, which is yellow-red - are found in human skin. It is known that the ratio of these two polymers determines skin color [12]. An increased proportion of pheomelanin is associated with lighter skin color [4]. Although melanin plays a key role in protecting the skin cells from UV damage, melanin production induced after exposure to UV radiation might cause skin changes such as sun tanning and mottled pigmentation [5]. Therefore, the control of pigmentation in human skin has been a longstanding goal for cosmetic and/or pharmaceutical applications.

Important factors that alter skin pigmentation in human are melanocytes that synthesize the melanin and neighboring keratinocytes that transport melanin to the higher layers of the skin [4]. Hesperidin that is a major component of our CPE neither inhibit melanin production in B16F10 murine melanoma cells stimulated with $\alpha$-melanocyte stimulating hormone nor affect the catalytic activity of tyrosinase. Instead, hesperidin inhibited melanosome transport in melanocytes and exerted a skin lightening effect in a pigmented reconstructed epidermis model [13].

Furthermore, oxidative stress that is induced by UV radiation is thought to play an important role in initiating and driving the signaling events that cause skin issues such as aging and pigmentation [14,15]. Oxidative stress, which causes various undesirable effects in the living body, is considered a major casual factor for aging and 
aging-related disease, and antioxidant substances such as vitamin $\mathrm{C}$ or a vitamin $\mathrm{E}$ are known to reduce such harmful effects. As the antioxidant ability of carotenoids is well known and believed to be beneficial for a healthy life, it is likely that our formula (AP-BF02) consisting of $\mathrm{CPE}$ and vitamin $\mathrm{C}$ possesses the potential to improve the quality of life through the alleviation of skin pigmentation as an antioxidant agent [16, 17]. Another component of AP-BF02 is L-cystine, a dimer of cysteine. It is reported that L-cystine regulates melanogenesis through the interaction with L-dopaquinone to form cysteinyl-dopa, which is converted and polymerized to pheomelanin able to decrease eumelanin level relatively $[4,18]$.

Oral supplementation for protecting skin damage has attracted attention nowadays. For systemic photo-protection, several compounds have been assessed for their ability to provide photo-protective activity after oral supplementation to develop new functional foods with skin benefits. However, there are few materials proven in a clinical trial [19,20,21]. According to this report, the various components of AP-BF02 are suggested to exert useful effects in skin brightening in human: (i) decreased melanin content through the inhibition of melanogenesis and the suppression of melanosome transport in melanocyte (by CPE), (ii) antioxidant activity against intracellular ROS stimulated by UVB (by vitamin C), and (iii) increased metabolic pathway to make pheomelanin associated with lighter skin color (by L-cystine).

As a mixture of these functional ingredients, AP-BF02 is expected to possess a strong skin lightening ability against harmful stress, and our study confirmed that AP-BF02 effectively alleviates skin pigmentation and is a new functional food for skin brightening.

\section{Conclusions}

In conclusion, in this study we firstly analyzed an 8-week-clinical trial for skin brightening effect of oral intake of a mixture containing natural CPE, vitamin C and L-cystine. The AP-BF02 formula can be considered as a good candidate as an ingredient of functional food for skin photo-protection, skin brightening, skin depigmentation and skin care.

\section{Acknowledgements}

This research was supported by AMOREPACIFIC Corporation. The authors thank Dermapro Skin Research Center as the site management organization for the clinical trial.

\section{Conflicts of Interest}

The authors declare no conflict of interest.
[2] Watanabe F, Hashizume E, Chan GP, Kamimira A. Skin-whitening and skin-condition-improving effects of topical oxidized glutathione: a double-blind and placebo-controlled clinical trial in healthy women. Clin Comet Invest Dermatol 7: 267-274 (2014).

[3] Wood J, Schallreuter K. Studies on the reactions between human tyrosinase, superoxide anion, hydrogen peroxide and thiols. Biochim Biophysic Acta 1074: 378-385 (1991).

[4] Gillbro JM, Olsson MS. The melanogenesis and mechanisms of skin-lightening agents - existing and new approaches. InternatJ Cosmet Sci 33: 210-221 (2011).

[5] Hanamura T, Uchida E, Aoki H. Skin-lightening effect of a polyphenol extract from acerola (Malpighia emarginata DC.) fruit on UV-induced pigmentation. Biosci Biotechnol Biochem 72(12): 3211-3218 (2008).

[6] Puglia C, Offerta A, Saija A, Trombetta D, Venera C. Protective effect of red orange extract supplementation against UV-induced skin damages: photoaging and solar lentigines. J Cosmet Dermatol 13: 151-157 (2013).

[7] Bae JT, Ko HY, Kim GB, Pyo HB, Lee GS. Protective effects of fermented citrus unshiu peel extract against ultraviolet-A-induced photoageing in human dermal fibroblasts. Phytother Res 26: 1851-1856 (2012).

[8] Yao X, Pan S, Duan C, Yang F, Fan G, Zhu X, Yang S, Xu X. Polymethoxylated Flavone Extracts from Citrus Peels for Use in the Functional Food and Nutraceutical Industry. Food Sci Biotechnol 18: 1237-1242 (2009).

[9] Prota G. Progress in the chemistry of melanins and related metabolites. Med Res Rev 8: 525-556 (1988).

[10] Yoshizaki N, Fujii T, Masaki H, Okubo T, Shimada K, Hashizume R. Orange peel extract, containing high level of polymethoxy-flavonoid, suppressed UVB-induced COX-2 expression and PGE2 production in HaCaT cells through PPAR-r activation. Experimental Dermatol 23: 18-22 (2014).

[11] Jo DJ, Seok JK, Kim SY, Park W, Baek JH, Kim YM, Boo YC. Human skin-depigmenting effects of resveratryl triglycolate, a hybrid compound of resveratrol and glycolic acid. Internat $\mathrm{J}$ Cosmet Sci 40: 256-262 (2018).

[12] Costin GE, Hearing VJ. Human skin pigmentation: melanocytes modulate skin color in response to stress. FASEB J 21: 976-994 (2007).

[13] Kim B, Lee JY, Lee HY, Nam KY, Park J, Lee SM, Kim JE, Lee JD, Hwang JS. Hesperidin suppressed melanosome transport buy blocking the interaction of Rab27A-melanophilin. Biomol Ther 21 343-348 (2013).

[14] Cardile V, Frasca G, Rizza L. Antiinflammatory effects of a red orange extract in human keratinocytes treated with interferongamma and histamine. Phytother Res 24: 414-418 (2010).

[15] Hwang JA, Park NH, Na YJ, Lee HK, Lee JH, Kim YJ, Lee CS. Coumestrol down-regulates melanin production in Melan-a murine melanocytes through degradation of tyrosinase. Biol Pharm Bull 40: 535-539 (2017).

[16] Chung I, Lee J, Park YS, Lim Y, Chang DH, Park J, Hwang JS. Inhibitory mechanism of Korean red ginseng on GM-CSF expression in UVB-irradiated keratinocytes. J Ginseng Res 39: 322-330 (2015).

[17] Park JI, Lee HY, Lee JE, Myung CH, Hwang JS. Inhibitory effect of 2-methyl-naphto[1,2,3-de]quinolin-8-one on melanosome transport and skin pigmentation. Sci Rep 6: 29189; (2016).

[18] Ryu JH, Seok JK, An SM, Baek JH, Koh JS, Boo YC. A study of the human skin-whitening effects of resveratryl triacetate. Arch Dermatol Res. 307: 239-247 (2015).

[19] Arjinpathana N, Asawanonda P. Glutathione as an oral whitening agent: a randomized, double-blind, placebo-controlled study. J Dermatolog Treat. 23(2): 97-102 (2012).

[20] Villarama CD, Maibach HI. Glutathione as a depigmenting agent; an overview. Int J Cosmet Sci 27(3): 147-153 (2005).

[21] Farris P, Krutmann J, Li YH, Mcdaniel D, Krol Y. Resveratrol: a unique antioxidant offering a multi-mechanistic approach for treating aging skin. J Drugs Dermatol 12:1389-1394 (2013).

\section{References}

[1] Masaki H. Role of antioxidants in the skin: anti-aging effects. J Dermatol Sci 58: 85-90 (2010). 